University of New Hampshire

University of New Hampshire Scholars' Repository

$6-2013$

\title{
Acoustic and optical observations of methane gas seeps in the Gulf of Mexico
}

Thomas C. Weber

University of New Hampshire, Durham, thomas.weber@unh.edu

Kevin W. Jerram

University of New Hampshire, Durham, kevin.jerram@unh.edu

Yuri Rzhanov

University of New Hampshire, Durham, Yuri.Rzhanov@unh.edu

Larry A. Mayer

University of New Hampshire, larry.mayer@unh.edu

Dave Lovalvo

NOAA

Follow this and additional works at: https://scholars.unh.edu/ccom

Part of the Oceanography and Atmospheric Sciences and Meteorology Commons

\section{Recommended Citation}

T. C. Weber, Jerram, K., Rzhanov, Y., Mayer, L. A., and Lovalvo, D., "Acoustic and optical observations of methane gas seeps in the Gulf of Mexico", Proceedings of Meetings on Acoustics, vol. 19. 2013.

This Conference Proceeding is brought to you for free and open access by the Center for Coastal and Ocean Mapping at University of New Hampshire Scholars' Repository. It has been accepted for inclusion in Center for Coastal and Ocean Mapping by an authorized administrator of University of New Hampshire Scholars' Repository. For more information, please contact Scholarly.Communication@unh.edu. 


\title{
Proceedings of Meetings on Acoustics
}
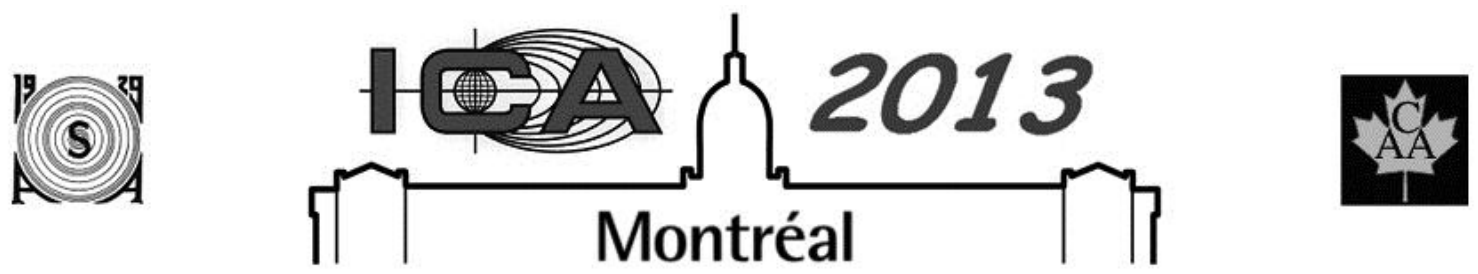

\author{
ICA 2013 Montreal \\ Montreal, Canada
}

2 - 7 June 2013

Biomedical Acoustics

Session 2pBAa: Bubbles Bubbles Everywhere II

\section{2pBAa10. Acoustic and optical observations of methane gas seeps in the Gulf of Mexico}

Thomas C. Weber*, Kevin Jerram, Yuri Rzhanov, Larry Mayer and Dave Lovalvo

*Corresponding author's address: Center for Coastal and Ocean Mapping, University of New Hampshire, Durham, NH 03824, weber@ccom.unh.edu

In 2011 and 2012, measurements of acoustic backscatter from natural methane seeps were made in the northern Gulf of Mexico in water depths between 1000-2000 m. The measurements were made using a calibrated $18 \mathrm{kHz}$ echo sounder with an 11 degree beamwidth in order to estimate the depth-dependent target strength (TS). The TS data indicate a wide variation in the rate of gas seepage from the seafloor. Several of these seeps were revisited with a remotely operated vehicle in order to optically assess the bubble size distribution and to estimate the rate at which gas bubbles were exiting the seafloor. The optical data show bubble sizes between 1-10 mm radius, and similar rates of gas seepage ranging from a few bubbles per second to several tens of bubbles per second. Together, these data help to suggest the requirements for acoustically estimating gas flux from the seafloor over large regions.

Published by the Acoustical Society of America through the American Institute of Physics 


\section{INTRODUCTION}

Natural seeps of methane gas rising from the ocean bottom are important to understand for several different reasons including the role they play in the global methane budget [Judd, 2004] as well as their linkage with chemosynthetic communities in the deep ocean [Fisher et al, 2007]. Acoustic observations made with echo sounders have been used several times over the past few decades to detect seeps of methane gas bubbles [e.g., Merewether et al., 1985, Hornafius et al., 1999; MacDonald et al., 2002, Heeschen et al., 2003, Greinert et al., 2006]. In this paper we similarly use an echo sounder to detect methane bubble seeps, but also examine the gas flux rate associated with these seeps by a) calibrating the echo sounder, b) using a split-beam (split-aperture correlator) to adjust the apparent target strength (TS) of the seep for the echo sounder beam pattern, and c) use optical images of bubbles on the seafloor collected with a remotely operated vehicle (ROV) in order to estimate bubble size. The data used in this paper were collected in the northern Gulf of Mexico, an oil and gas province in which natural methane seeps are generally known to be present [Roberts and Carney, 1997].

\section{TARGET STRENGTH MEASUREMENTS OF METHANE BUBBLE SEEPS}

Acoustic backscatter data from methane bubble seeps were collected using an $18 \mathrm{kHz}$ Simrad EK60 split-beam echosounder with a nominal $11^{\circ}$ beamwidth on board the NOAA Ship Okeanos Explorer. This echo sounder was calibrated using a standard target method [Foote et al., 1987]. A piston transducer model was fit to the calibration data, making it possible to compensate measurements of apparent TS for the transducer beam pattern. Only data for which beam pattern corrections was less than $6 \mathrm{~dB}$ (1-way) were used in this analysis. An example echogram showing three seeps, including apparent TS (i.e., with no adjustment for the transducer beam pattern) and both the along-track and across-track target angle measurements, is shown in Figure 1. Three individual seeps are present, all of which have been imaged within a few degrees of the beam MRA in the across-track direction. In each case, the along-track mechanical angle changes in accordance with the traverse of the ship across the target. The mechanical angles can be used to georeference the positions of the bubbles comprising the seep, which have a lateral extent that is small compared with the beam footprint at the depths of observation, and can also be used to estimate the true TS by adjusting for the beam pattern. The latter processing step is of interest here.

Seep TS data were extracted from the acoustic data from several seeps, including those shown in Figure 1, by selecting only those targets that had a both a signal-to-noise ration greater than $10 \mathrm{~dB}$ and a 1-way beam pattern adjustment that was no greater than $6 \mathrm{~dB}$. Depth-dependent noise levels were extracted from 20-30 ping averages of acoustic data where no seeps were found, and are presented as equivalent TS measurements in Figure 2. Seep TS are also shown in Figure 2 for three different locations in the northern Gulf of Mexico: the Pascagoula Dome, the Biloxi Dome, and the Gloria Dome. Note that the three seeps shown in Figure 1 are the same seeps presented in the middle panel of Figure 2. These observations suggest that the seep TS is variable over a range of at least -34 to -20 $\mathrm{dB}$. Seeps are observed to rise as high as $600 \mathrm{~m}$ in the water column.

Assuming, for the sake of comparison, that these seeps were comprised of $3 \mathrm{~mm}$ radius bubbles at their respective bases (in approximately 1130, 1380, and $1570 \mathrm{~m}$ water depth), the number of bubbles in a $1 \mathrm{~m}$ tall column required to generate the seep TS observations in Figure 2 would range from 11 bubbles $/ \mathrm{m}$ at the Biloxi Dome to 440 bubbles $/ \mathrm{m}$ at the Gloria Dome. Assuming the bubbles are rising at a speed of $20 \mathrm{~cm} / \mathrm{s}$ and that the seeps are steadily seeping all day, this would be an equivalent range in volume flux of gas at depth of $0.02-0.9$ $\mathrm{m}^{3} /$ day. 

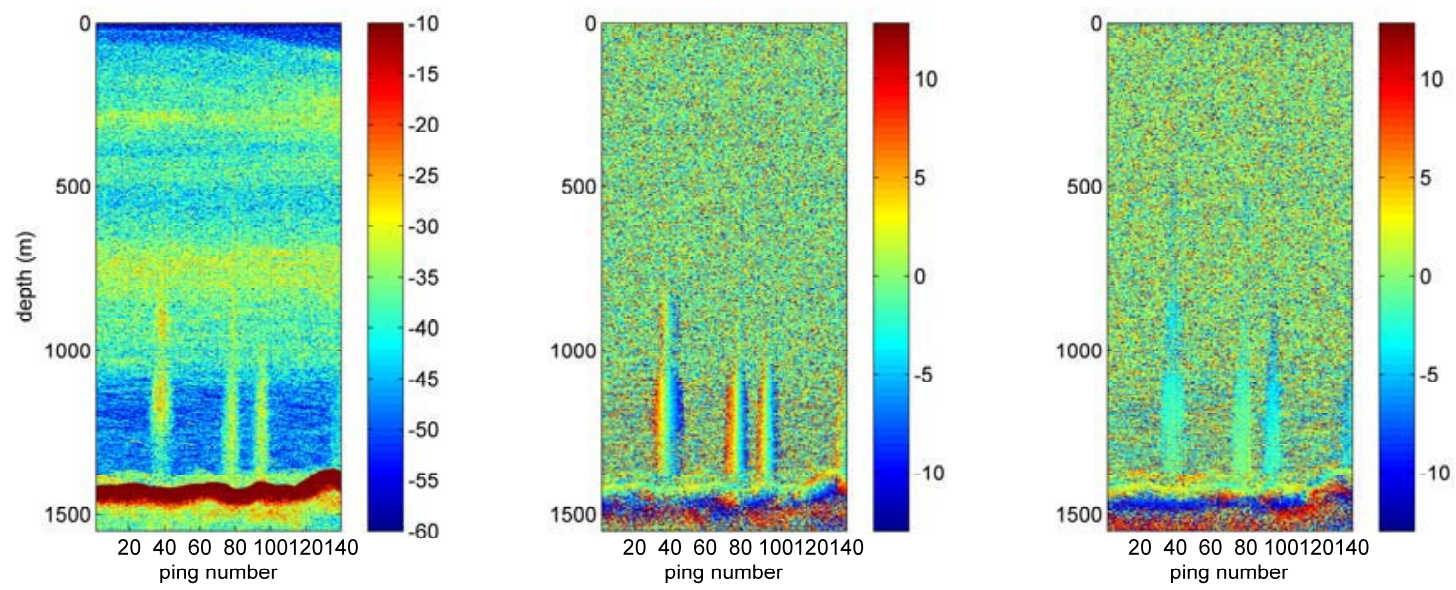

FIGURE 1. An echogram showing apparent TS in dB (left), the along-track target angle in degrees (middle), and the across-track target angle in degrees (right).
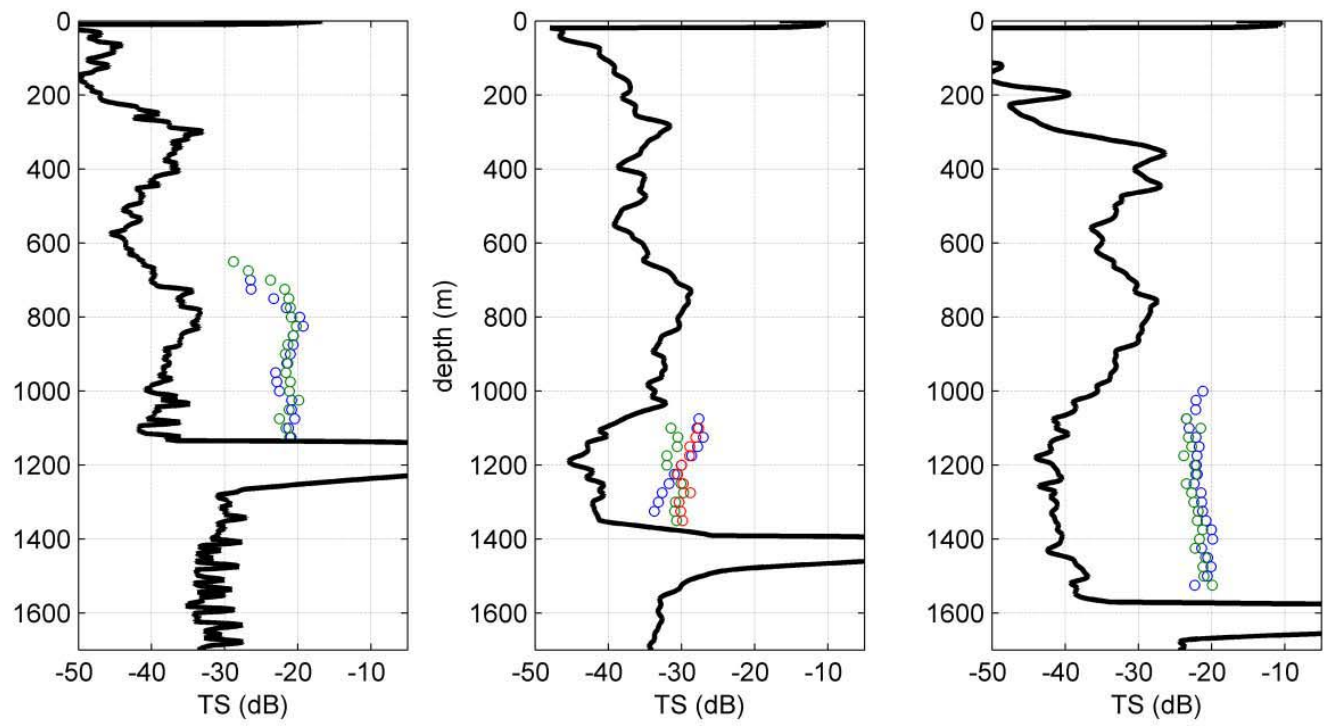

FIGURE 2. Examples of depth-dependent seep target strength data (colored circles) for the Pascagoula Dome (left), Biloxi Dome (middle), and Gloria Dome (right). The background noise - presented as equivalent TS, are shown as black lines.

\section{OPTICAL BUBBLE SIZE MEASUREMENTS}

Several seeps were also visited with the Little Hercules ROV deployed from the Okeanos Explorer. Little Hercules contains a high-definition video camera, and for one of its dives was outfitted with a grid designed for optically measuring a bubble size distribution. ROV dives were conducted on the Pascagoula dome, the Biloxi Dome, and at a site several $\mathrm{km}$ south of the Biloxi Dome. Although this was by no means an exhaustive survey of the seeps present in this area, video data suggested that the bubbles were quite variable in terms of their size and rate. Figure 3 shows bubbles seeping from each of the three areas visited. Seeps observed at the Biloxi dome were found to have the slowest rate of bubble production and, for the specific seep shown in Figure 3 (left) seemed to form only bubbles of size $1.4 \mathrm{~mm}$ radius or $3.1 \mathrm{~mm}$ radius (measured using $10 \mathrm{~cm}$-spaced laser dots illuminating the carbonate formation from which the bubbles were observed to be escaping). At the site south of Biloxi several sources of bubbles in close proximity $(<1 \mathrm{~m}$ apart) were found, with the most rapid seep containing bubbles with a size of approximately $1.5 \mathrm{~mm}$ radius (Figure 3, middle). At the Pascagoula dome a seep was observed with a wider range of bubble sizes (Figure 3, right) ranging from approximately 1-7 $\mathrm{mm}$ in radius. 

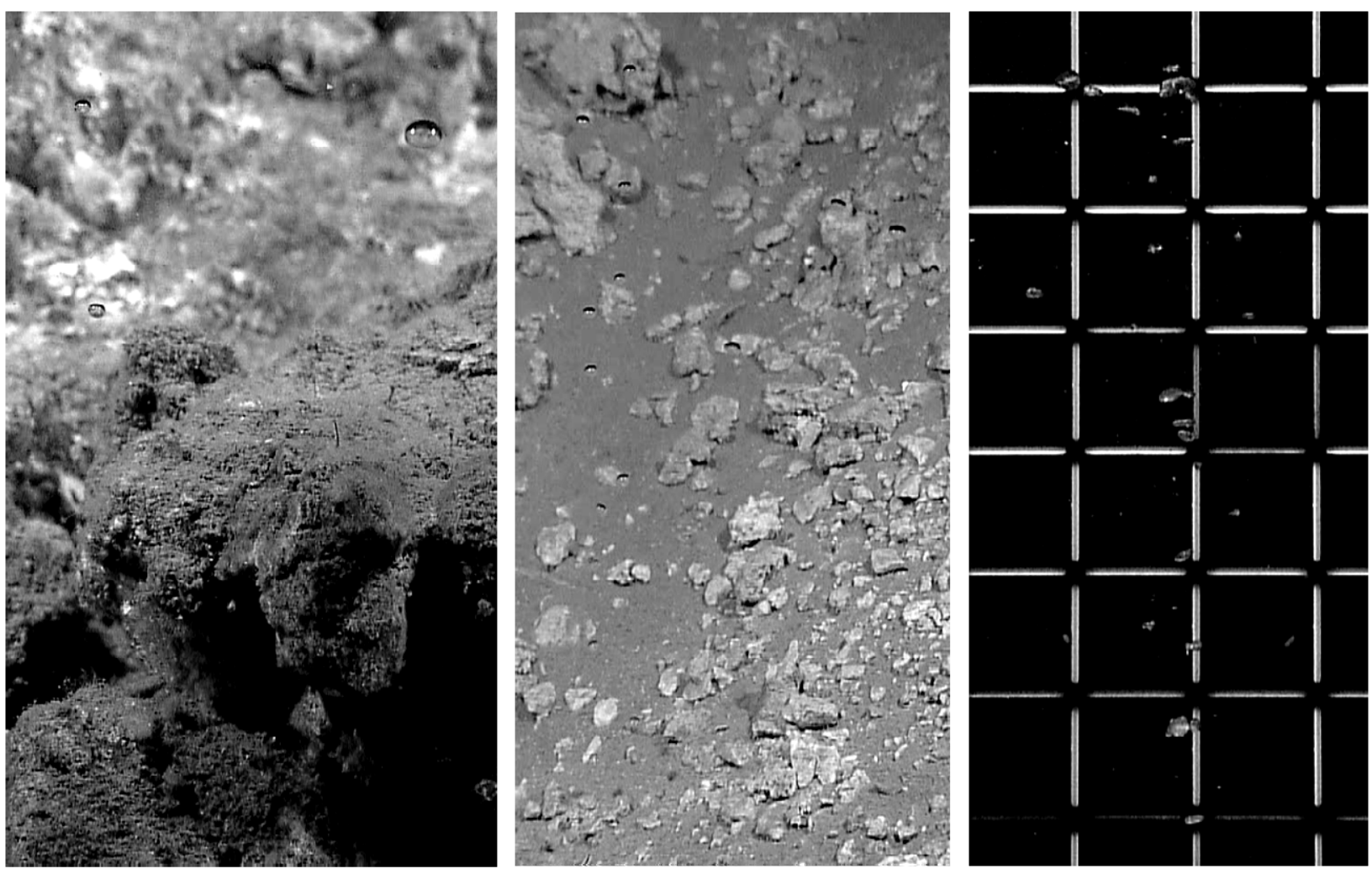

FIGURE 3. Optical imagery from seeps collected with Little Hercules. Left: Biloxi Dome; Middle: South of the Biloxi Dome; Right: Pascagoula Dome.

\section{DISCUSSION}

Methane bubble seeps rising through the water column in the northern Gulf of Mexico, in water depths ranging from 600-1500 m, have been observed to have target strength differences of up to $14 \mathrm{~dB}$ near the ocean bottom. Optical measurements also show variability (between seeps, at least) in both bubble size (variable, between 1-7 mm) and rate of bubble generation. The acoustic measurements were made at a single frequency $(18 \mathrm{kHz})$, and are quite sensitive: the Biloxi Dome data (Figure 1) suggest that the echo sounder can easily detect as few as 11 bubbles per vertical meter of the plume. It is important to note that the size of a resonating bubble at $18 \mathrm{kHz}$, at the depths under consideration here, are close to $3 \mathrm{~mm}$. Together, calibrated measurements of acoustic backscatter combined with optical measurements of bubble size can provide a measurement of gas flux from the seabed. The acoustic measurements are far easier to collect in comparison to the optical measurements ( 1-2 seeps per dive), but the variable nature of the seeps observed here suggest that care must be taken when extrapolating a few 'ground-truthed' seeps to acoustically-observed seeps across an entire oil and gas province.

\section{ACKNOWLEDGMENTS}

This work was supported under NOAA grant NA05NOS4001153. We would like to acknowledge the efforts of the captain, crew, and science party aboard Okeanos Explorer during the collection of these data.

\section{REFERENCES}

Fisher, C., H. Robers, E. Cordes, and B. Bernard Cold seeps and associated communities of the Gulf of Mexico, Oceanography 20(4). (2007)

Foote, K. G., H. P. Knudsen, G. Vestnes, D. N. MacLennan, and E. J. Simmonds. 1987. Calibration of acoustic instruments for fish density estimation: a practical guide. ICES Coop. Res. Rep. No. 144, 69 p. 
Greinert, J., Y. Artemov, V. Egorov, M. De Batist, and D. McGinnis, 1300-m-high rising bubbles from mud volcanos at $2080 \mathrm{~m}$ in the Black Sea: Hydroacoustic characteristics and temporal variability, Earth and Plan. Sci. Let. 244. (2006).

Heeschen, K., A. Trehu, R. Collier, E. Suess, and G. Rehder, Distribution and height of methane bubble plumes on the Cascadia Margin characterized by acoustic imaging, Geophys. Res. Let 30. (2003).

Hornafius, J., D. Quigley, B. Luyendyk, The world's most spectactular marine hydrocarbon seeps (Coal Oil Point, Santa Barbar Channel, California): quantification of emission, J. Geophys. Res. 104, 20703-20711. (1999).

Judd, A.G., Natural seabed gas seeps as sources of atmospheric methane, Environmental Geology 46, 099-996. (2004)

MacDonald, I. R., I. L. R. Sassen, P. Stine, R. Mitchell, and N. J. Guinasso Transfer of hydrocarbons from natural seeps to the water column and atmosphere, Geofluids, 2, 95-107. (2002)

Merewether, R., M.S. Olsson, P. Lonsdale, Acoustically detected hydrocarbon plumes rising from 2-km depths in the Guayamas Basin, Gulf of California, J. Geophys. Res. 90, 3075-3085 (1985).

Roberts, H.H. and R.S. Carney, Evidence of episodic fluid, gas, and sediment venting on the northern Gulf of Mexico continental slope. Economic Geology 92:863-879. (1997). 